Ciência Florestal, Santa Maria, v. 23, n. 3, p. 281-289, jul.-set., 2013

ISSN 0103-9954

\title{
ALTERAÇÕES NA ARQUITETURA TÍPICA DE Tipuana tipu (Benth.) O. Kuntze NA ARBORIZAÇÃO DE RUAS DE CURITIBA, PARANÁ
}

\author{
CHANGES IN THE TYPICAL ARCHITECTURE OF Tipuana tipu (Benth.) O. Kuntze ON STREET \\ TREES OF CURITIBA, PARANÁ
}

\author{
Rogério Bobrowski ${ }^{1}$ Everaldo Marques de Lima Neto ${ }^{2}$ Daniela Biondi ${ }^{3}$
}

\begin{abstract}
RESUMO
A estrutura e os equipamentos urbanos podem restringir o correto desenvolvimento das árvores e de sua arquitetura típica. A Tipuana tipu (Benth.) O. Kuntze (tipuana) tem sido podada de forma contínua por ser uma espécie de grande porte e por estar entre as mais plantadas na cidade de Curitiba. Por conta disso, o presente trabalho teve por objetivo avaliar a alteração da arquitetura típica de Tipuana tipu na arborização de ruas de Curitiba, por meio de delineamento inteiramente casualizado contendo uma parcela testemunha composta por 6 árvores, um tratamento com 6 árvores sob fiação e outro com 6 árvores em ruas livres de fiação. A partir de fotografias horizontais das árvores foram obtidas variáveis dendrométricas, tendo por base uma escala métrica acoplada à altura do DAP. Assim, foram calculados índices morfométricos para descrever relações interdimensionais para a espécie, em árvores sem poda (testemunha) e em árvores podadas (tratamentos). Os resultados demonstraram que as podas de elevação alteram a arquitetura típica da tipuana modificando seu contorno e sua forma, além de prejudicar seu efeito estético. Os índices que podem expressar as alterações, de forma significativa $(p<0,05)$, foram: índice de abrangência, índice de saliência, ângulo de copa, proporção de copa e relação HR/HP.
\end{abstract}

Palavras-chave: práticas silviculturais; podas; copas; manejo de árvores urbanas.

\begin{abstract}
The urban structure and equipments can restrict the correct development of trees and its typical architecture. Tipuana tipu (Benth.) O. Kuntze (rosewood) has been pruned continuously for being a species of large size and for being the most planted tree in the city of Curitiba. Because of that, this work aimed to assess the changes in the typical architecture of Tipuana tipu on street trees of Curitiba through completely randomized design containing a check plot composed by 6 trees and a treatment with 6 trees under utility lines and another with 6 trees in streets without utility lines. From horizontal photographs of trees there were obtained dendrometric variables based on a metric scale attached at DBH. Thus, the morphometric indexes were calculated to describe dimensional relationships for the species on trees without pruning (check plot) and on pruned trees (treatments). The results showed that raising pruning change typical architecture of rosewood modifying its outline and its form, in addition to harm its aesthetic effect. The indexes that can express changes significantly $(p<0.05)$, were: range index, salience index, crown angle, crown proportion and relation $\mathrm{RH} / \mathrm{PH}$.
\end{abstract}

Keywords: forestry practices; pruning; canopies; management of urban trees.

1 Engenheiro Florestal, MSc., Doutorando em Engenharia Florestal pela Universidade Federal do Paraná, Departamento de Pesquisa e Monitoramento, CEP 80000-00, Curitiba (PR). bobrowski_roger@yahoo.com.br

2 Engenheiro Florestal, MSc., Doutorando em Engenharia Florestal pela Universidade Federal do Paraná, Professor Assistente do Departamento de Engenharia Florestal, Universidade Estatual de Roraima, CEP 69373-970, Rorainópolis (RR).netofloresta@yahoo.com.br

3 Engenheira Florestal, Dra., Professora Associada do Departamento de Ciências Florestais, Universidade Federal do Paraná, CEP 80210-170, Curitiba (PR).dbiondi@ufpr.br

Recebido para publicação em 14/06/2011 e aceito em 27/03/2012

Ci. Fl., v. 23, n. 3, jul.-set., 2013 


\section{INTRODUÇÃO}

Os procedimentos silviculturais adotados no gerenciamento da arborização urbana visam criar e manter benefícios e condições apropriadas à população, diminuindo conflitos com equipamentos urbanos (postes, redes de fiação, sinalização, etc) e riscos potenciais que surgem da interação árvores-pessoas-estruturas. Estes procedimentos envolvem ações como: escolha de espécies apropriadas, planejamento da coleta de sementes, adequada produção de mudas, eficiência nas técnicas de plantio e correta aplicação da técnica e da intensidade de poda.

Ações como a poda dependem de ferramentas e maquinários adequados, além do conhecimento da época mais apropriada à execução. Entretanto, os limites máximos e a real necessidade desse tipo de intervenção nem sempre são ponderados e aplicados com critério pelo órgão responsável. Desse fato decorrem as deformações da arquitetura típica das espécies e os problemas consequentes. Neste sentido, Biondi e Althaus (2005) afirmaram que a poda está entre as práticas de manutenção que proporcionam maior intervenção no vegetal e impacto visual.

De acordo com Durlo et al. (2004), procedimentos silviculturais como a determinação do espaço de crescimento (concorrência máxima) e as avaliações de estabilidade, vitalidade e produtividade das árvores, especialmente quando não se conhece a idade das plantas, são dependentes de informações como a largura, a altura e a área de copa, das proporções entre esses fatores e das modificações sofridas por ações de manejo pretéritas. Estas observações foram reforçadas por Roman et al. (2009) quando afirmaram que o conhecimento da morfometria, das relações morfométricas e da dinâmica da forma das árvores são fatores importantes para intervenções silviculturais e utilização de espécies nativas em reflorestamentos.

As técnicas de avaliação da morfometria e das relações morfométricas, com estudos e aplicações progressivas no manejo de florestas plantadas e nativas, mediante análise de árvores individuais ou associadas na floresta (TONINI; ARCO-VERDE, 2005; ORZEL, 2007; ROMAN et al., 2009), ainda não foram aplicadas na silvicultura urbana. Isto poderia auxiliar no conhecimento das relações interdimensionais, do comportamento individual e da interação entre as árvores nas ruas, bem como auxiliar a adoção de melhores critérios de planejamento da implantação de espécies em uso ou que serão incorporadas na arborização, além do estabelecimento de limites aceitáveis de intervenção por podas.

A arquitetura das espécies florestais é definida pelo genótipo que determina as características de porte, forma da copa, disposição das folhas e flores. A junção do conhecimento dessas características com noções de fisiologia da compartimentalização, tipos de poda e equipamentos necessários para executá-la favorece a adoção de boas práticas de manejo, evitando danos às árvores (SEITZ, 1996).

Segundo Schumacher e Poggian (1993), a arquitetura da copa das árvores afeta a produtividade primária do ecossistema regulando fatores como temperatura, umidade, vento e iluminação. Disso decorre a necessidade de se respeitar limites máximos de intervenção por poda, a fim de se manter os benefícios almejados com a implantação das árvores nas vias públicas. Por outro lado, o conhecimento das características de cada espécie deve ser a base para a escolha de espécies para a arborização urbana, pois facilitará a posterior manutenção das copas por meio da poda (SEITZ, 1996).

Este trabalho teve por objetivo geral, avaliar a alteração da arquitetura típica de Tipuana tipu (Benth.) O. Kuntze (tipuana) na arborização de ruas de Curitiba. Os objetivos específicos propostos foram: analisar os índices morfométricos que descrevem as relações interdimensionais da espécie; analisar os índices que conseguem descrever as alterações da arquitetura de copa devido a podas de elevação.

\section{MATERIAL E MÉTODOS}

\section{Caracterização da área de estudo}

A pesquisa foi desenvolvida na arborização de ruas de Curitiba, capital do Estado do Paraná. A cidade está localizada na região leste do Estado, na latitude $25^{\circ} 25^{\prime} 40^{\prime}$ 'S e longitude 49 $16^{\prime} 23^{\prime}$ 'W (Marco Zero - Praça Tiradentes) (Figura 1), em região de clima do tipo Cfb na classificação de Köppen. O clima é definido como subtropical úmido, mesotérmico, sem estação seca, com verões frescos e invernos com geadas frequentes. As médias de temperatura são de $20^{\circ} \mathrm{C}$ no verão (período 2000/2009) e $14^{\circ} \mathrm{C}$ no inverno (período de 2000 a 2009). A altitude média é de $934 \mathrm{~m}$ acima do nível do mar e a área do município é de $435 \mathrm{~km}^{2}$, com extensão de $35 \mathrm{~km}$ no sentido norte-sul e $20 \mathrm{~km}$ no sentido leste-oeste (IPPUC, 2010).

Para a realização do presente estudo, foram selecionados exemplares adultos de Tipuana 

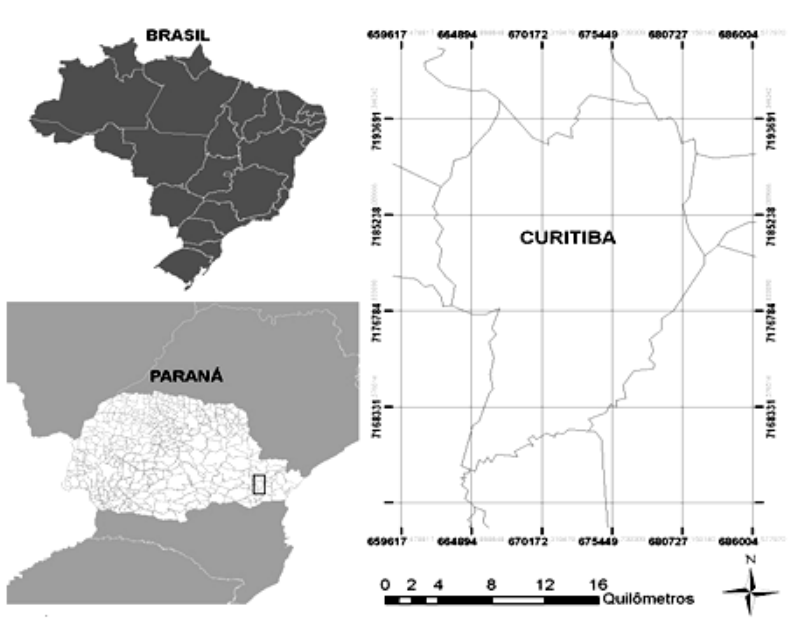

FIGURA 1: Localização geográfica de Curitiba, Paraná.

FIGURE 1: Geographic location of Curitiba, Paraná state.

tipu (Benth.) O. Kuntze na arborização de ruas de Curitiba, a qual é apontada por Bobrowski (2011) como uma das espécies mais frequentes na arborização da cidade. Para Lorenzi (2003), ela está entre as mais utilizadas na arborização de ruas, avenidas e praças do sul e sudeste do Brasil, sendo considerada de crescimento rápido e de grande porte.

\section{Procedimentos metodológicos}

$\mathrm{O}$ experimento estabelecido foi o delineamento inteiramente casualizado, com uma parcela testemunha composta por 6 árvores e 2 tratamentos com 6 árvores cada, totalizando 18 árvores de
Tipuana tipu (Benth.) O. Kuntze avaliadas. Utilizando as informações do inventário contínuo da arborização de ruas de Curitiba-PR, realizado por Bobrowski (2011) foram sorteadas duas ruas arborizadas com tipuana para compor os tratamentos. Para compor o tratamento testemunha foram selecionadas as seis primeiras árvores isoladas que foram encontradas nas imediações das ruas sorteadas para avaliação. Os tratamentos adotados encontravam-se em três situações distintas (Figuras 2A, 2B e 2C), sendo:

Tratamento 1 (T01) - Árvores isoladas em praças, terrenos particulares e canteiros centrais (testemunhas), as quais não apresentavam sinais de interferências por podas de elevação e desta maneira expressavam a arquitetura típica da espécie. Salienta-se que todas as árvores avaliadas como testemunha estavam localizadas em canteiros permeáveis, com área maior que $6,0 \mathrm{~m}^{2}$ (Figura 2A);

Tratamento 2 (T02) - Árvores em calçada sob fiação de redes de transmissão de energia elétrica, com influência de poda de elevação (Figura 2B);

Tratamento 3 (T03) - Árvores em calçada sem fiação, com influência de poda de elevação (Figura 2C).

O trabalho de campo consistiu em efetuar a tomada de fotografias horizontais com máquina fotográfica digital modelo Nikkon Coolpix 8.0M, sendo que para cada árvore foram obtidos pares de fotografias perpendiculares entre si e tendo por base o alinhamento do meio-fio.

A mensuração de cada fotografia foi realizada por meio do software Corel Draw X3, a partir
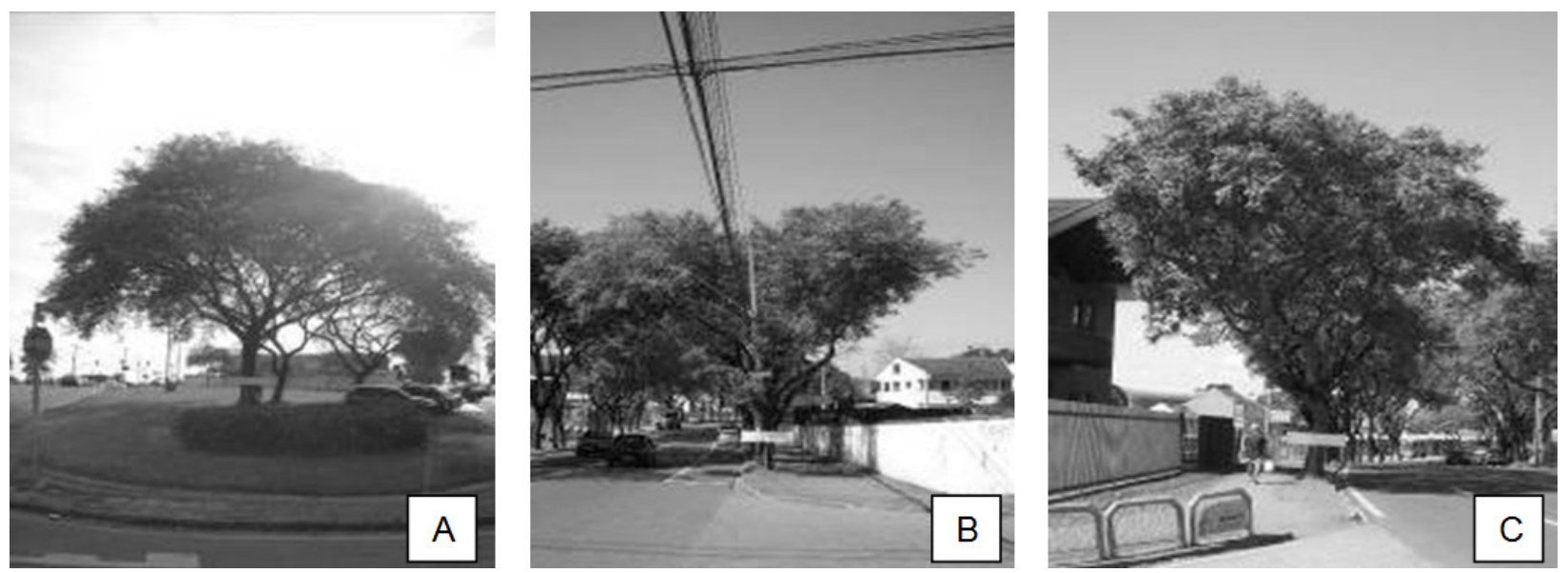

FIGURA 2: Tratamentos analisados. A: Árvore testemunha; B: Árvore sob fiação de transmissão de energia elétrica; C: Árvore em calçada sem fiação.

FIGURE 2: Treatments analyzed. A: Tree control; B: Trees under utility lines; C: Trees on sidewalk without utility lines. 
do conhecimento das dimensões da escala gráfica $(1,50 \mathrm{~m} \times 0,35 \mathrm{~m})$ acoplada ao tronco da árvore a $1,30 \mathrm{~m}$ do solo (Figura 3 ).

A escala métrica foi elaborada para realizar medições e acessar informações morfométricas, baseada na metodologia utilizada por Durlo et al. (2004), os quais efetuaram medições em copas de Cedrela fissilis com uso de fotografias digitais, escala métrica acoplada à árvore e procedimento para correção do ângulo de inclinação da máquina digital.

Em campo, foram obtidas medidas do CAP (circunferência a altura do peito), com uso de uma trena, e da altura total, com auxílio de um hipsômetro de Blume-Leiss. No laboratório, a partir de cada fotografia, foram obtidas as seguintes variáveis: Altura Total (HT), medida da base da árvore ao topo da copa; Altura Real de Copa (HR), medida da linha inferior à linha superior da copa existente (massa verde); Altura Potencial de Copa (HP) medida da bifurcação ao topo da copa; Altura de bifurcação (HBIF); Ângulo da Copa (ANG), estabelecido como o ângulo aferido das extremidades da copa em relação ao ponto central do fuste na altura de bifurcação; Raios da copa, que somados resultaram na largura da copa; (Figura 4).

Para cada árvore foram analisados cinco índices de morfometria visando descrever as relações interdimensionais em cada uma delas. De acordo com Durlo e Denardi (1998), os índices são assim descritos:

a) Proporção de Copa (PC): relação entre a altura real de copa (HR) e a altura total da árvore (HT);

b) Índice de Saliência (IS) - relação entre a largura da copa e o DAP;

c) Índice de Abrangência (IA) - relação entre a largura da copa e a altura total da árvore;

d) Formal de Copa (FC): relação entre o diâmetro de copa e a altura da mesma;

e) Grau de Esbeltez (GE): relação entre altura total da árvore (HT) e DAP;

Os dados foram processados em planilhas eletrônicas do software Microsoft Office Excel 2007 e as análises estatísticas foram feitas no software Assistat versão 7.5.

\section{RESULTADOS E DISCUSSÃO}

Os valores da análise morfométrica e demais informações para as copas das árvores de tipuana, tanto daquelas em condições de crescimento sem interferências, quanto daquelas que apresentaram intervenções por podas, encontram-se na Tabela 1.

Para o índice ângulo da copa (ANG) foram obtidos valores superiores a $130^{\circ}$ para a testemunha (T01) enquanto que para os tratamentos (T02 e T03) os valores máximos não ultrapassaram $94^{\circ}$. Isto indica que a poda de elevação efetuada nas árvores por motivos diversos tende a modificar a forma da copa e seu real contorno. Este fato é reforçado pela diferença observada no índice proporção de copas, pois para a testemunha o valor mínimo observado
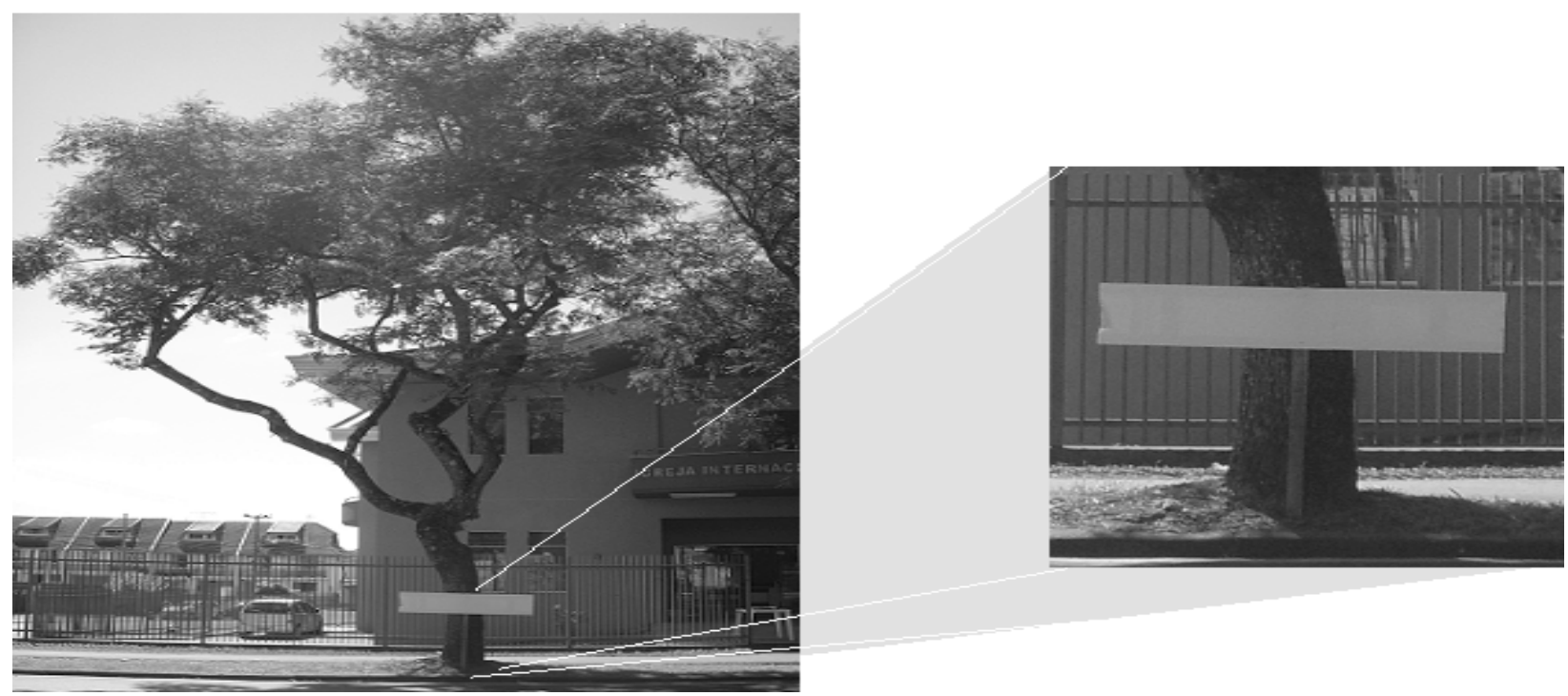

FIGURA 3: Escala métrica (1,50x 0,35 metros) acoplada nas árvores de rua.

FIGURE 3: Metric scale (1.50 x 0.35 meters $)$ attached to street trees. 


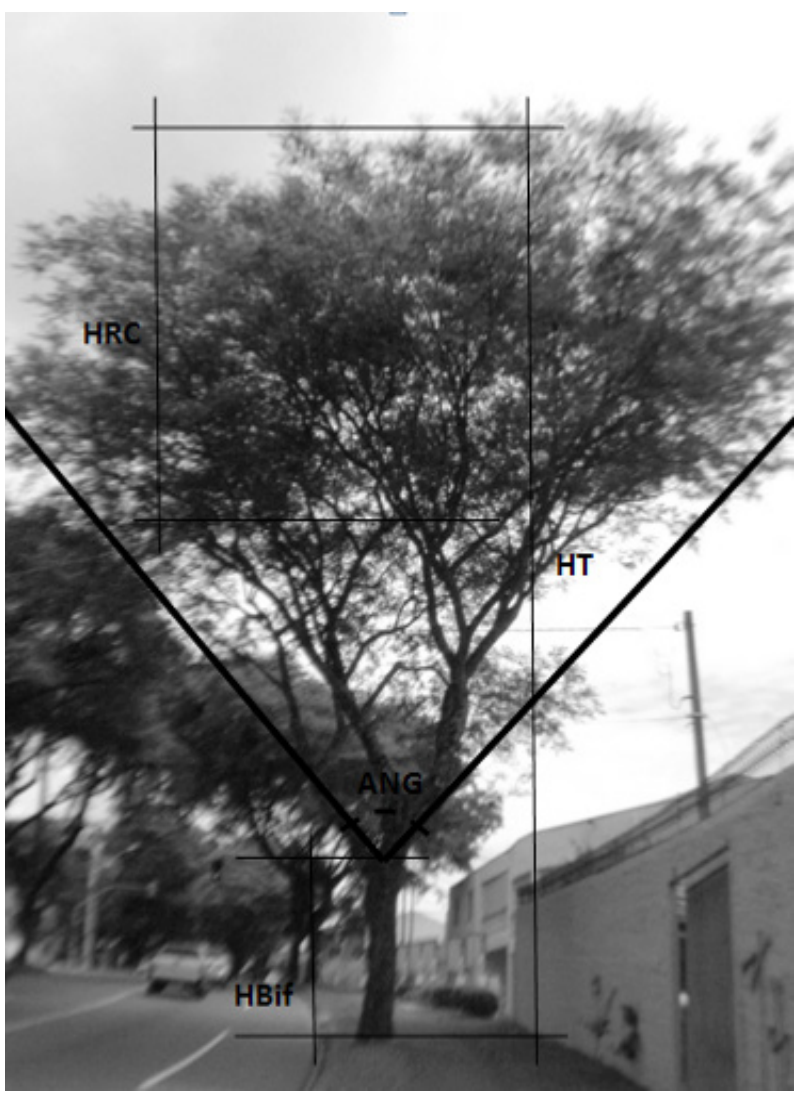

FIGURA 4: Modelo representativo de variáveis dendrométricas medidas nas fotografias.

FIGURE 4: Representative model of dendrometric variables measured on the photographs. foi igual a $64 \%$ enquanto que para os tratamentos o valor máximo foi igual a $59 \%$. Ambas as disparidades dos índices, dos tratamentos em relação à testemunha, demonstraram que a proporção de massa verde da copa das árvores de tipuana tende a ser menor em situação de interferência por podas de elevação.

Com relação à razão $\mathrm{HR} / \mathrm{HP}$, observa-se que para a testemunha os valores variaram entre 0,83 e 1,00 , enquanto que para os tratamentos os valores são menores e variaram entre 0,41 e 0,74 . Isto demonstra que os maiores valores da razão HR/ HP estão relacionados à maior aproximação das árvores à condição natural da arquitetura típica. $\mathrm{O}$ menor valor para a razão HR/HP indica maior redução da área das copas pelas podas de elevação, e por consequência maior alteração da arquitetura típica. Entretanto, mesmo em condições naturais de crescimento, sem intervenções, as copas das árvores podem sofrer alteração na relação HR/HP por conta do sombreamento e declínio dos galhos inferiores da copa.

De acordo com Roman et al. (2009), quanto maior o valor do Índice Grau de Esbeltez (GE) mais instável é a árvore. Para os dois tratamentos adotados, os valores de GE encontrados variaram entre 23,86 e 33,82, enquanto que para a testemunha os valores variaram entre 17,78 e 31,99 . Apesar das intervenções por poda de elevação nos tratamentos, os valores obtidos para este índice não indicaram

TABELA 1: Dimensões das copas de Tipuana tipu (Benth.) O. Kuntze e resultados da análise morfométrica. TABLE 1: Tipuana tipu (Benth.) O. Kuntze canopies dimensions and morphometric analysis results.

\begin{tabular}{c|cccc|cccc|cccc}
\hline Variáveis e & \multicolumn{4}{|c|}{ Valores tratamento 1 } & \multicolumn{4}{c|}{ Valores tratamento 2 } & \multicolumn{4}{c}{ Valores tratamento 3 } \\
\cline { 2 - 12 } Índices & Mín & Méd & Máx & CV(\%) & Mín & Méd & Máx & CV $(\%)$ & Mín & Méd & Máx & CV(\%) \\
\hline DAP (m) & 0,17 & 0,46 & 0,58 & 32,50 & 0,4 & 0,6 & 0,78 & 24,63 & 0,3 & 0,56 & 0,91 & 39,38 \\
H total (m) & 5,50 & 10,92 & 14 & 28,73 & 10 & 16,17 & 21 & 29,38 & 10 & 16,17 & 24 & 31,88 \\
H bif (m) & 1,60 & 2,41 & 3,19 & 25,11 & 1,8 & 2,51 & 3,8 & 27,80 & 1,87 & 2,8 & 3,53 & 22,36 \\
HR copa (m) & 3,54 & 7,78 & 9,62 & 29,05 & 4,31 & 7,15 & 10,18 & 30,13 & 4,32 & 6,7 & 10,8 & 37,92 \\
HP copa (m) & 3,90 & 8,50 & 11 & 30,76 & 7,91 & 13,78 & 18,2 & 33,55 & 8,13 & 13,37 & 21,25 & 36,06 \\
Razão HR/HP & 0,83 & 0,92 & 1,00 & 6,78 & 0,35 & 0,48 & 0,92 & 45,51 & 0,3 & 0,46 & 0,67 & 26,77 \\
ANG (graus) & 138 & 158 & 176 & 8,04 & 75 & 86 & 92 & 7,62 & 78 & 83 & 93 & 7,07 \\
PC & 64,36 & 71,06 & 77,56 & 7,39 & 35,92 & 44,74 & 58,90 & 17,89 & 31,43 & 41,19 & 45,21 & 13,21 \\
GE & 17,78 & 24,96 & 31,99 & 22,17 & 23,86 & 26,53 & 30,12 & 8,38 & 26,36 & 29,77 & 33,42 & 8,75 \\
IS & 30,32 & 34,48 & 43,49 & 13,58 & 21,70 & 25,55 & 35,80 & 20,57 & 19,22 & 26,49 & 34,34 & 21,14 \\
IA & 1,12 & 1,41 & 1,77 & 15,55 & 0,72 & 0,97 & 1,42 & 25,32 & 0,73 & 0,88 & 1,03 & 12,69 \\
FC & 1,73 & 1,99 & 2,28 & 10,89 & 1,49 & 2,20 & 2,91 & 21,56 & 1,62 & 2,20 & 3,12 & 25,05 \\
\hline
\end{tabular}

Em que: Htotal (Altura Total da Árvore), Hbif (Altura de Bifurcação), HR (Altura Real da Copa), HP (Altura Potencial da Copa); ANG (Ângulo da Copa); PC (Proporção de Copa); GE (Grau de Esbeltez); IS (İndice de Saliência); IA (Índice de Abrangência); FC (Formal de Copa) 
situação de instabilidade e necessidade de remoção de indivíduos. Além disso, os baixos valores encontrados para a via pública podem indicar a adaptação das árvores às condições ambientais locais, apresentando maior crescimento em diâmetro para suportar o crescimento em altura e manter a estabilidade estrutural da árvore, pois, conforme resultados obtidos por Selle e Vuaden (2010), as árvores, de um modo geral, tendem a diminuir seu grau de esbeltez à medida que aumenta a dimensão do DAP.

O Índice de Saliência (IS) e o Índice de Abrangência (IA), segundo Roman et al. (2009), são indicativos do espaço necessário ao crescimento de uma árvore, pois expressam quantas vezes a copa é maior que o DAP ou que a altura da árvore, respectivamente. Desta forma, são úteis para se verificar alterações promovidas por podas de elevação excessiva, podas incorretas ou por competição de copas, pois expressam as alterações promovidas sobre as proporções naturais que a árvore apresenta em con- dições de crescimento livre. Para as tipuanas avaliadas foi encontrado valor médio igual a 34,48 de IS e de 1,41 de IA para a testemunha, enquanto que para os tratamentos (T02 e T03, respectivamente) foram obtidos valores médios de 25,55 e 26,49 para o IS e 0,88 e 0,97 para o IA. Nota-se que as diferenças entre os valores desses índices entre a testemunha e os tratamentos também indicam alterações da copa promovidas pelas podas de elevação.

Houve diferença estatisticamente significativa entre os tratamentos adotados e a testemunha $(p<0,05)$ para os índices: proporção de copa, índice de saliência, índice de abrangência, ângulo de copa, altura potencial e razão HR/HP (Tabelas 2, 3, 4 e 5), com baixo coeficiente de variação.

Para o índice formal de copa (FC) foram obtidos valores entre 1,73 e 2,28 para a testemunha e 1,49 e 3,12 para os tratamentos. Estes valores sugerem que sob condições naturais de crescimento a copa das árvores tende a manifestar uma relação di-

TABELA 2: Análise de variância dos índices morfométricos de Tipuana tipu (Benth.) O. Kuntze.

TABLE 2: Analysis of variance of Tipuana tipu (Benth.) O. Kuntze morphometric indexes.

\begin{tabular}{ccccccc}
\hline Fonte de & Graus de & \multicolumn{5}{c}{ Quadrado Médio } \\
\cline { 3 - 7 } Variação & Liberdade & PC & GE & IS & IA & FC \\
\hline Tratamento & 2 & $1597,297^{*}$ & $36,13319^{\text {ns }}$ & $144,4138^{*}$ & $0,48648^{*}$ & $0,08918^{\text {ns }}$ \\
\hline CV(\%) & 10,79 & 14,74 & 16,93 & 19,63 & 17,56 \\
$\chi^{2}$ & $1,64^{\text {ns }}$ & $4,63^{\text {ns }}$ & $0,15^{\text {ns }}$ & $2,28^{\text {ns }}$ & $3,66^{\text {ns }}$ \\
\hline
\end{tabular}

Em que: PC (Proporção de Copa), GE (Grau de Esbeltez); IS (Índice de Saliência); IA (Índice de Abrangência); FC (Formal de Copa); (ns) não significativo; $(*)$ estatisticamente significativo $(p<0,05)$.

TABELA 3: Comparação de médias dos índices morfométricos

TABLE 3: Mean comparison test of morphometric indexes.

\begin{tabular}{ccccccccccc}
\hline Fonte de Variação & \multicolumn{1}{c}{ PC } & GE & & IS & \multicolumn{3}{c}{ IA } & \multicolumn{2}{c}{ FC } \\
\hline Tratamento 1 & 71,06 & a & 24,96 & a & 34,48 & a & 1,42 & a & 1,99 & a \\
Tratamento 2 & 44,74 & b & 26,53 & a & 25,55 & b & 0,97 & b & 2,19 & a \\
Tratamento 3 & 41,19 & b & 29,77 & a & 26,49 & b & 0,88 & b & 2,19 & a \\
\hline
\end{tabular}

Em que: PC (Proporção de Copa); GE (Grau de Esbeltez); IS (Índice de Saliência); IA (Índice de Abrangência); FC (Formal de Copa). Médias seguidas pela mesma letra não diferem estatisticamente.

TABELA 4: Análise de variância dos índices de copa de Tipuana tipu (Benth.) O. Kuntze.

TABLE 4: Analysis of variance of Tipuana tipu (Benth.) O. Kuntze crown indexes.

\begin{tabular}{cccccc}
\hline \multirow{2}{*}{ Fonte de Variação } & Graus de & \multicolumn{4}{c}{ Quadrado Médio } \\
\cline { 2 - 6 } & Liberdade & ANG & HR & HP & RZHRHP \\
\hline Tratamento & 2 & $10763,72^{*}$ & $1,76988^{\text {ns }}$ & $51,69576^{*}$ & $0,32561^{*}$ \\
\hline $\mathrm{CV}(\%)$ & 9,02 & 23,81 & 24,13 & 11,81 \\
$\chi^{2}$ & $3,385^{\text {ns }}$ & $0,135^{\text {ns }}$ & $1,815^{\text {ns }}$ & $2,754^{\text {ns }}$ \\
\hline
\end{tabular}

Em que: ANG (Ângulo de copa), HR (Altura Real), HP (Altura Potencial); RZHRHP (Razão Altura Real/Altura Potencial). (ns) não significativo; $(*)$ estatisticamente significativo $(p<0,05)$. 
TABELA 5: Comparação de médias dos índices de copa.

TABLE 5: Mean comparison test of crown indexes.

\begin{tabular}{ccccccccc}
\hline Fonte de Variação & ANG & HR & \multicolumn{2}{c}{ HP } & \multicolumn{2}{c}{ RZHRHP } \\
\hline Tratamento 1 & 158,42 & a & 7,78 & a & 8,50 & b & 0,920 & a \\
Tratamento 2 & 86,25 & b & 7,15 & a & 13,78 & a & 0,534 & b \\
Tratamento 3 & 83,92 & b & 6,70 & a & 13,37 & a & 0,502 & b \\
\hline
\end{tabular}

Em que: ANG (Ângulo de Copa), HR (Altura Real), HP (Altura Potencial); RZHRHP (Razão Altura Real/Altura Potencial). Médias seguidas pela mesma letra não diferem estatisticamente.

âmetro de copa/DAP mais homegênea (representada pela menor amplitude de valores), enquanto que sob condições de intervenção silvicultural por podas há tendência a menor homogeneidade dos valores (representados pela maior amplitude de valores). Entretanto, para este índice não houve diferença estatisticamente significativa entre a testemunha e os tratamentos $(p>0,05)$.

Mesmo sendo constatadas intervenções por poda de elevação e alteração da arquitetura original da espécie, os valores do índice formal de copa (FC) sugerem que as árvores mantiveram a forma básica da massa verde aproximada a um paraboloide, ou seja, uma copa umbeliforme. No entanto, esta forma se apresentou em condição levemente mais achatada para os tratamentos, ou seja, alterada, pois menor foi o valor médio da altura de copa e maiores foram os valores do índice. Segundo Orellana e Koehler (2008), quanto maiores os valores deste índice, mais achatada é a copa da árvore.

A análise do coeficiente de correlação de Spearman revelou que há forte correlação positiva entre os índices PC e IA $(0,825)$ e entre os índices IA e IS $(0,728)$, além de moderada correlação positiva entre os índices PC e IS $(0,571)$ (Tabela 6).

A alta correlação entre as variáveis PC/IA e IA/IS deve-se às características em comum para a composição delas: a altura da árvore para o PC e IA e a largura de copa para o IS e IA.

Ainda, pode-se constatar que houve alta correlação entre o índice ângulo da copa e os índices proporção de copa, índice de abrangência e índice razão HR/HP (Tabela 6). Isto se deve ao fato de que quanto mais intensa a poda de elevação, menor é o ângulo da copa e o valor do índice razão HR/HP e maiores são os valores dos índices PC e IA, pois mais restritas são a altura e a largura da copa.

De acordo com Biondi e Althaus (2005), a forma da copa de tipuana é descrita na literatura como flabeliforme, umbeliforme ou arredondada. No entanto, as observações feitas nesta pesquisa mostraram que sob condições de crescimento livre de interferências por poda de elevação, a espécie tende a apresentar a copa com forma umbeliforme, com ângulo de copa próximo a $180^{\circ}$. A mudança para a forma flabeliforme, com ângulo de copa próximo a $90^{\circ}$, ocorre à medida que se efetuam podas de elevação, com diminuição do comprimento de copa, do ângulo da mesma e da massa verde, por consequência. Para ambas as situações, a forma da copa (massa verde) se assemelha a um paraboloide, para fins de cálculo de área e de volume.

TABELA 6: Correlação simples entre os índices de alteração da arquitetura.

TABLE 6: Simple correlation among architecture change indexes.

\begin{tabular}{ccccccccc}
\hline & PC & GE & IS & IA & FC & ANG & HP & RZHRHP \\
\hline PC & 1 & & & & & & & \\
GE & $-0,527$ & 1 & & & & & & \\
IS & 0,571 & 0,106 & 1 & & & & & \\
IA & 0,825 & $-0,591$ & 0,728 & 1 & & & & \\
FC & $-0,377$ & 0,004 & 0,241 & 0,194 & 1 & & & \\
ANG & 0,929 & $-0,469$ & 0,649 & 0,852 & $-0,171$ & 1 & & \\
HP & $-0,488$ & 0,109 & $-0,829$ & $-0,744$ & $-0,391$ & $-0,576$ & 1 & \\
Razão HR/HP & 0,987 & $-0,477$ & 0,663 & 0,863 & $-0,289$ & 0,951 & $-0,586$ & 1 \\
\hline
\end{tabular}

Em que: PC (Proporção de Copa); GE (Grau de Esbeltez); IS (Índice de Saliência); IA (Índice de Abrangência); FC (Formal de Copa); ANG (Ângulo de Copa), HR (Altura Real), HP (Altura Potencial); RZHRHP (Razão Altura Real/ Altura Potencial). 
Em plantios antigos de tipuana em Curitiba, como na Avenida Getúlio Vargas, as árvores foram manejadas para que a copa fosse elevada acima da fiação de alta tensão $( \pm 12 \mathrm{~m}$ de altura), porém, com a fiação de baixa tensão ( $\pm 5 \mathrm{~m}$ de altura) passando logo acima da altura de bifurcação. Isto faz com que a forma das árvores se aproxime do tipo flabeliforme.

Mesmos em calçadas livres de fiação aérea, as árvores desta espécie quando plantadas em espaçamentos restritos também podem apresentar modificações na forma da copa mais precocemente devido ao entrelaçamento dos galhos e morte dos mesmos. O aumento da concorrência entre copas propicia a morte de galhos pequenos por diminuição da incidência lumínica e, desta forma, mais frequentes são as necessidades de poda para fins de limpeza da copa e eliminação de riscos ao tráfego local. A incidência de erva-de-passarinho, comum em tipuanas, também pode favorecer práticas de poda mais pesadas, intensas ou frequentes.

Um dos principais problemas gerados pela poda de elevação excessiva é o desequilíbrio estrutural da árvore, pois à medida que se altera a arquitetura típica ocorre a diminuição da proporção natural de ramos e folhas. Segundo James (2003), isto diminui a capacidade da árvore em dissipar a carga dinâmica do vento e evitar que esta energia chegue diretamente ao tronco principal ou galhos de maior porte ocasionando rupturas. Isto corrobora com a afirmação de Gilman e Lilly (2002) de que a poda de elevação excessiva pode causar, além da redução do crescimento, a transferência de peso para o topo da árvore.

Com menor proporção de ramos e folhas, pode-se promover maior balanço, oscilação e possibilidade de ruptura de troncos de porte ou da árvore como um todo, pois também será maior o grau de esbeltez para os galhos. A tipuana, folhosa com arquitetura de copa plagiotrópica (SEITZ, 1996), tende a formar galhos de porte tão grandes quanto o próprio tronco, a fim de sustentar a carga estática criada em função de seu crescimento.

Dessa forma, as podas de elevação excessiva efetuadas na tentativa de diminuir a carga estática da copa podem potencializar a ação da carga dinâmica do vento e a ruptura dos galhos de porte. Para Harris (1992), o local de maior fragilidade estrutural nas folhosas é exatamente o ponto de junção de galhos ao tronco, devido ao porte que podem desenvolver. De acordo com Gilman e Lilly (2002), a remoção de galhos de grande porte, nas podas de elevação, propicia o surgimento de cancros, declínio e podridão do tronco, pois gera estresse fisiológico e a redução da estabilidade.

Para cada espécie há proporções adequadas para os diversos tipos de poda (limpeza, raleamento, elevação e rebaixamento), a fim de não afetar a estabilidade estrutural, visando procurar melhorar as condições fitossanitárias da árvore e de segurança das vias públicas e diminuir os riscos potenciais de danos (PAVLIS et al., 2008).

Para as espécies florestais utilizadas na composição da arborização urbana brasileira, ainda não há critérios técnicos e normativos para orientar as interferências por poda, com limites máximos aceitáveis, obedecendo à forma, contorno, área e volume da arquitetura típica da espécie sem afetar a estabilidade estrutural, momentos de tração e flexão limitantes à ruptura da árvore como um todo.

A partir do estresse fisiológico gerado pela poda pode ocorrer a emissão de brotações epicórmicas e consequentemente potencializar riscos, principalmente diante de intensidades inadequadas de poda para determinada espécie, pois as brotações epicórmidas consitituem um tipo de defeito estrutural pela característica de união fraca ao tronco (SEITZ, 1996; ALBERS et al. 2003). O ideal seria conduzir as mudas e árvores jovens até o limite de altura e espaço disponível, evitando-se intervenções pesadas com poda de galhos de grande porte ou podas com grande remoção de massa verde as quais potencializam a emissão de brotações epicórmicas.

Por esta razão, podas de elevação excessiva não deveriam ser justificadas além da altura de tráfego da via, pois, podem prejudicar a qualidade estética e a estabilidade estrutural da espécie, pela influência na distribuição de carga ou favorecimento da emissão de brotações epicórmicas.

\section{CONCLUSÕES}

As podas de elevação alteram a arquitetura típica da Tipuana tipu (Benth.) O. Kuntze modificando seu contorno e sua forma, além de influenciar seu efeito estético.

Os índices proporção de copa, de saliência, de abrangência, ângulo de copa e a razão HR/HP, podem ser utilizados para descrever as alterações promovidas na arquitetura típica da espécie.

Para os índices avaliados não houve diferença na mensuração da alteração da arquitetura da espécie para árvores localizadas em calçadas com ou sem fiação de transmissão de energia elétrica. 


\section{REFERÊNCIAS BIBLIOGRÁFICAS}

ALBERS, J. S.; POKORNY, J. D.; JOHNSON, G. R. How to dectect and assess hazardous defects in trees. In: POKORNY, J. D. (Coord.). Urban tree risk management: a community guide to program design and implementation. St. Paul: USDA, Forest Service, Northeastern Area, Staty and Private Forestry, 2003. chap. 3, p. 41-116. (Technical Paper, NA-TP-03-03).

BIONDI, D.; ALTHAUS, M. Árvores de rua de Curitiba: cultivo e manejo. Curitiba: FUPEF, 2005. BOBROWSKI, R. Estrutura e dinâmica da arborização de ruas de Curitiba, Paraná, no período 1984 - 2010. 144 f. Dissertação (Mestrado em Engenharia Florestal) - Setor de Ciências Agrárias, Universidade Federal do Paraná, Curitiba, 2011.

DURLO, M. A.; DENARDI, L. Morfometria de Cabralea canjerana, em mata secundária nativa do Rio Grande do Sul. Ciência Florestal, Santa Maria, v. 08, n. 01, p. 55-66. 1998.

DURLO, M. A.; SUTILI, F. A.; DENARDI, L. Modelagem da copa de Cedrela fissilis Vellozo. Ciência Florestal, Santa Maria, v. 14, n. 2, p. 7989. 2004.

GILMAN, E. F.; LILLY, S. J. Best Management Practices: Tree Pruning. Champaign: ISA, 2002. $35 \mathrm{p}$.

HARRIS, R. W. Arboriculture: integrated management of landscape trees, shrubs and vines. 2nd ed. New. Jersey: Prentice Hall, 1992.

IPPUC. Curitiba em Dados. Curitiba: IPPUC, jun. 2010. Disponível em: http://www.ippuc.org.br/ informando/curitibaemdados.htm. Acesso em 25 de junho de 2010.

JAMES, K. Dynamic loading of trees. Journal of Arboriculture, Champaign, v. 29, n. 03, p. 165171, 2003.

LORENZI, H. Árvores exóticas no Brasil: madeira, ornamentais e aromáticas. Nova Odessa: Plantarum, 2003. $382 \mathrm{p}$.

ORELLANA, E.; KOEHLER, A. B. Relações morfométricas de Ocotea odorifera (Vell.) Rohwer. Revista Acadêmica de Ciências Agrárias e Ambientais, Curitiba, v. 6, n. 2, p. 229-237, 2008. ORZEL, S. A comparative analysis of slenderness of the main tree species of the Niepolomice Forest. Eletronic Journal of Polish Agricultural Universities, Cracow, v. 10, n. 02, 2007. Disponível em: <http://www.ejpau.media.pl/volume10/issue2/ art-13.html $>$. Acesso em: 14/10/2010.

PAVLIS, M.; et al. The effects of pruning on drag and bending moment of shade trees. Arboriculture and Urban Forestry, Champaign, v. 34, n. 04, p.207215, 2008.

ROMAN, M.; BRESSAN, D. A.; DURLO, M. A. Variáveis morfométricas e relações interdimensionais para Cordia trichotoma (Vell.) Arráb. ex Steud. Ciência Florestal, Santa Maria, v. 19, n. 4, p. 473-480. 2009.

SCHUMACHER, M. V.; POGGIAN, F. Caracterização microclimática no interior dos talhões de Eucalyptus camaldulensis Dehnh, Eucalyptus grandis Hill ex Maiden e Eucalyptus torelliana F. Muell, localizados em Anhembi, SP. Ciência Florestal, Santa Maria, v. 03, n. 1, p. 0920. 1993.

SEITZ, R. A. A Poda de Árvores Urbanas. Piracicaba: IPEF. Curso em Treinamento sobre Poda em Espécies Arbóreas Florestais e de Arborização Urbana, 1, Piracicaba, São Paulo, 1996. p. 27.

SELLE, G. L.; VUADEN, E. Crescimento de seis espécies nativas na região central do estado do Rio Grande do Sul. Ambiência, Guarapuava, v. 06, n. 01, p. 169-192. 2010.

TONINI, H.; ARCO-VERDE, M. F. Morfologia da copa para avaliar o espaço vital de quatro espécies nativas da Amazônia. Pesquisa Agropecuária Brasileira, Brasília, v. 40, n. 7, p. 633-638, 2005. 